\title{
Análise do sistema separador absoluto no âmbito da drenagem pluvial da cidade de Campina Grande - Estudo de caso do Canal das Piabas.
}

\author{
Analysis of absolute separator system within the rainwater drainage of Campina Grande city - \\ Case study of the Piabas Canal
}

\author{
Josefa Rafaela Pessoa Freire', Patricia Herminio Cunha Feitosa², Mônica De Amorim Coura³, \\ Maria Jôsiane Caminha ${ }^{4}$
}

\author{
1,3 Mestranda em Engenharia Civil e Ambiental na Universidade Federal de Campina Grande - UFCG - PB - Brasil \\ 2,4Professora do Programa de Pós-graduação Engenharia Civil e Ambiental da Universidade Federal de Campina Grande - UFCG - PB - Brasil
}

\begin{abstract}
Resumo
A cidade de Campina Grande tem apresentado sérios problemas de alagamentos e inundações nos períodos de chuva, gerados pela deficiência na gestão do sistema separador absoluto adotado, bem como pelo precário investimento no setor de saneamento, contribuindo para a existência de riscos epidemiológicos e ambientais. Este trabalho teve como objetivo analisar o sistema separador absoluto no âmbito da drenagem pluvial da cidade de Campina Grande, com base no estudo de caso do canal das Piabas. Ao longo do canal foram selecionadas cinco pontos de amostragem, para avaliar o comportamento das características das águas. Os indicadores de qualidade da água adotados neste trabalho foram turbidez, SST, DBO, DQO, OD e CTT, com a finalidade de identificar a existência de contaminação por esgoto. Avaliando-se os resultados dos indicadores analisados foi observado que, todos os pontos apresentaram contaminação por esgoto, sendo o ponto P1o que se encontra menos poluído, evidenciando a ocorrência do aporte de esgoto ao longo do canal. Foi concluído que a água do canal das Piabas se caracteriza como esgoto doméstico fraco, mostrando assim, que o sistema adotado não funciona como separador absoluto, expondo a população a riscos epidemiológicos, e comprometendo a qualidade dos corpos receptores.
\end{abstract}

Palavras-chave: Sistema separador absoluto; drenagem pluvial urbana; riscos epidemiológicos e ambientais.

\begin{abstract}
The city of Campina Grande has presented serious problems of water logging and flooding during the rainy season, generated by a deficiency in the management of the absolute separation system adopted, as well as the poor investment in the sanitation sector, contributing to the existence of epidemiological and environmental risks. This study aimed to analyze the absolute separation system in the context of rainwater drainage of Campina Grande, based on the case study of the canal of Piabas. Along the canal five sample points were selected to evaluate the behavior of the water quality. The indicators of water quality adopted in this work were turbidity, TSS, BOD, COD, DO and CTT, in order to identify the existence of contamination by sewage. Evaluating the results of the indicators analyzed was observed that all points were contaminated by sewage, and the point $\mathrm{P} 1$ which is less polluted, evidencing the occurrence of sewage contribution along the canal. It was concluded that water of canal of Piabas characterized as weak domestic sewage, thereby showing that the system adopted does not work as an absolute separator, exposing the population to epidemiological risks, and affecting the quality of receiving bodies.
\end{abstract}

Keywords: Absolute separator system; urban rainwater drainage; epidemiological and environmental risks. 


\section{INTRODUÇÃO}

A urbanização ocorrida nas últimas décadas, notadamente nos países em desenvolvimento, dentre os quais o Brasil, é um dos fatores responsáveis pelo agravamento dos problemas relacionados às inundações nas cidades, aumentando a frequência e os níveis das cheias. Isto ocorre devido à impermeabilização crescente das bacias hidrográficas, e à ocupação inadequada das regiões ribeirinhas aos cursos d'água (RAMOS et al., 1999).

Para Nóbrega (2012), Campina Grande apresentou um acelerado processo de urbanização nos últimos anos, novas áreas foram ocupadas favorecendo o aumento do escoamento superficial, provocado por obras de pavimentação, que impermeabilizam o solo, e a construção dos mais diversos tipos de edificações. Consequentemente, a cidade tem apresentado sérios problemas nos períodos de chuva, gerados pelo grande acúmulo do volume de água escoada superficialmente. A falta de investimentos do poder público na expansão dos sistemas de drenagem urbana e as falhas dos sistemas que se encontram implantados também contribuem para o fenômeno de inundação das bacias urbanas.

Um fato evidente neste cenário de desenvolvimento é que as cidades não estão preparadas para esse crescimento, pois, entre outros problemas, em geral os sistemas de saneamento básico também não estão preparados para o aumento na demanda por água potável e geração de águas residuárias. No Brasil, segundo o Sistema Nacional de Informação sobre Saneamento - SNIS (2011), o atendimento de água potável é de $82,4 \%$ quando consideradas as áreas urbanas e rurais do País, e o atendimento em coleta de esgotos chega apenas a $48,1 \%$ da população brasileira. A outra parte da população que não tem acesso a esses serviços vive em ambientes insalubres suscetíveis às doenças, uma vez que os investimentos em saneamento não acompanham o crescimento populacional.

Diante de tal situação é notória a importância da crescente preocupação com o saneamento básico, uma vez que, este está relacionado diretamente com as questões de saúde pública. Desta forma, os sistemas de saneamento básico surgem com o objetivo de amenizar esses problemas.

Apesar, dos avanços no setor, ainda estamos longe de atingir uma situação ideal, visto que, em determinadas circunstâncias, percebemos alguns retrocessos. Um exemplo são os sistemas de esgotamento sanitário do tipo separador absoluto que têm sido adotados nas cidades brasileiras. Nesses, águas de drenagem e águas residuárias devem ser conduzidas em condutos diferentes, mas, na prática, na maioria do tempo, ambas são veiculadas em um único canal configurando-se como um sistema separador parcial. É perceptível que há uma deficiência na gestão desses sistemas e neste sentido, torna-se importante analisar a aplicação do sistema separador absoluto.

A presente pesquisa teve como objetivo principal, analisar o sistema separador absoluto no âmbito da drenagem pluvial da cidade de Campina Grande, com base no estudo de caso do Canal das Piabas.

\section{METODOLOGIA}

\subsection{Caracterização da área de estudo}

A presente pesquisa foi realizada na cidade de Campina Grande. Seu município está localizado no interior do estado da Paraíba, mais precisamente no agreste paraibano, situado entre as regiões do baixo e médio curso do Rio Paraíba. Mesmo com o sistema separador absoluto, a cidade vem enfrentando problemas com a ocorrência de inundações que aumentam a cada ano, isso devido ao crescimento desordenado, ao uso do solo associado às práticas inadequadas de disposição de resíduos sólidos e líquidos nos sistemas de drenagem, como também ao limitado controle de operação e manutenção das estruturas físicas desses sistemas.

O sistema de esgotamento sanitário de Campina Grande estende-se por três bacias (Figura 4.2), sendo duas bacias que contribuem para a estação de tratamento do bairro da Catingueira - a bacia Depuradora e a bacia Bodocongó - e uma bacia que contribui para a estação de tratamento do bairro Glória - bacia Glória. É constituído de dois interceptores principais (Interceptor da Depuradora - Leste e Interceptor de Bodocongó - Oeste), um emissário (Emissário da Catingueira), duas Estações de Tratamento de Esgoto (bairro Catingueira e bairro Glória) e cinco elevatórias (LIMA, 2013).

A drenagem da cidade de Campina Grande é composta por um sistema de microdrenagem como bocas de lobo, sarjetas, poços de visitas, tubos de ligação e galerias, e um de macrodrenagem 
que compreende canais trapezoidais e retangulares, em sua maioria abertos. Dentre os canais, têmse o canal das Piabas, do Prado, de Bodocongó, da Ramadinha, das Malvinas, de Santa Rosa, entre outros, construídos com o objetivo de afastar as águas pluviais o mais rápido possível e conduzi-las para os corpos hídricos mais próximos.

O Canal das Piabas, localizado na zona norte de Campina Grande (Figura 1), tem início no bairro do Louzeiro, perpassa pelos bairros Conceição, Alto Branco, Lauritzen, Santo Antônio, Centro, Monte Castelo e, por fim, se encaminha para José Pinheiro (zona leste) onde deságua. Há uma bifurcação em seu percurso, uma se direciona para o Açude Velho (que só contribui em picos de chuvas), e a outra para o bairro José Pinheiro.

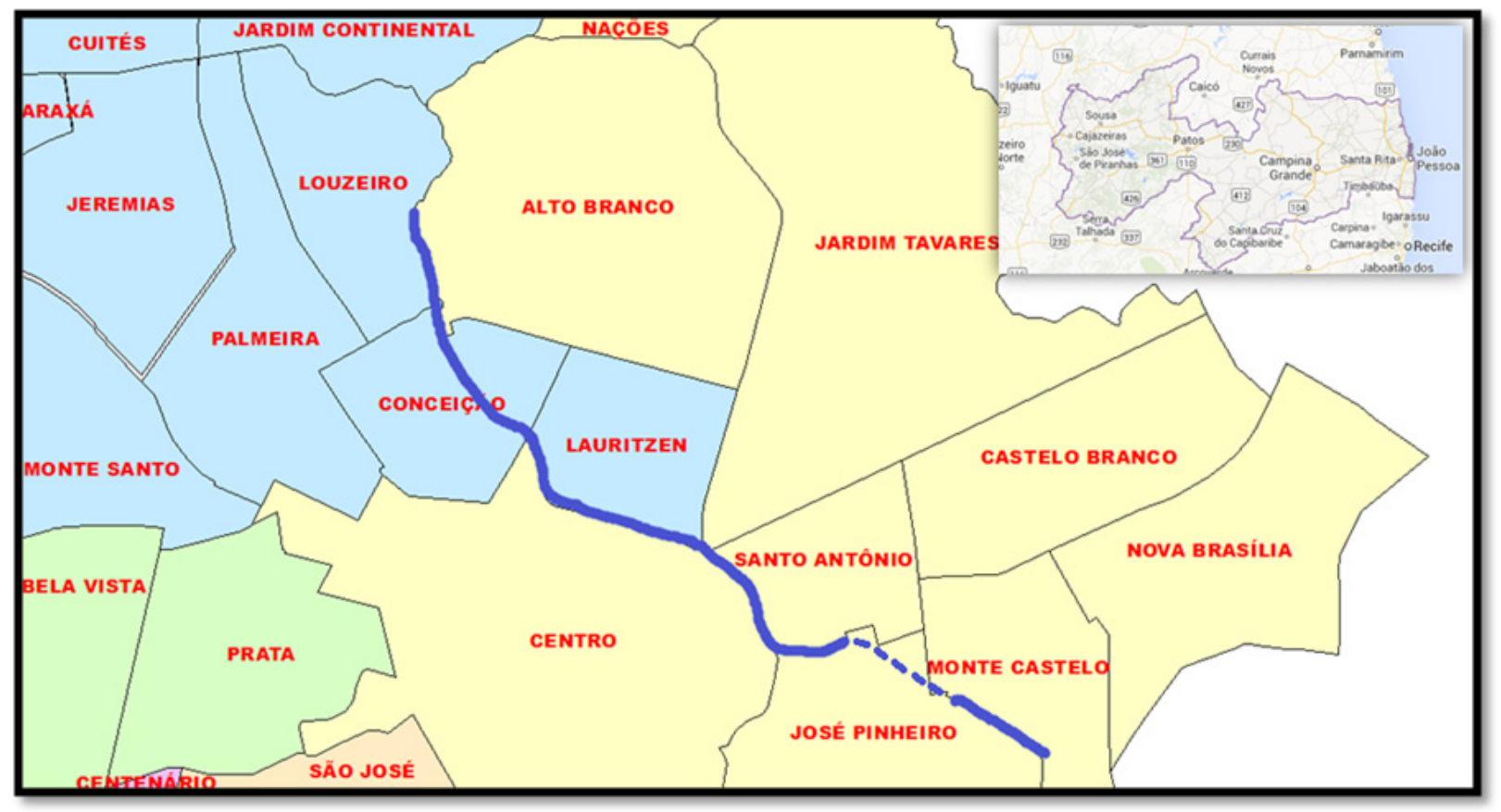

Figura 1 - Mapa de localização do canal das Piabas nos bairros de Campina Grande.

Fonte: Google imagens.

Nas imediações do bairro Rosa Mística o riacho começa a ser canalizado e, sua água, antes perene, tem se reduzido a um "fio" em períodos de estiagem. Nessa época os esgotos domésticos chegam a representar a quase totalidade da sua vazão, seguindo o curso de ligação urbana pela Avenida Canal e posteriormente para o bairro da Cachoeira de onde prossegue com destino ao Rio Paraíba (SOUSA, 2010).

Apesar de ser dotada de sistema de esgotamento, a cidade enfrenta alguns problemas quanto ao lançamento de esgoto a céu aberto e nos corpos hídricos, além da presença de ligações clandestinas de esgotos na rede de drenagem pluvial, isto se deve à ausência ou deficiência do sistema adotado, bem como à falta de controle e fiscalização dos usuários dos sistemas.

\subsection{Pontos de amostragem}

Diante dos problemas recorrentes associados à ocorrência de inundações e disposição inadequada de resíduos líquidos e sólidos nos canais de drenagem de Campina Grande e especialmente no Canal das Piabas, foram selecionadas cinco pontos de amostragem (Figura 2), para avaliar o comportamento das características das águas ao longo do canal.

Os pontos para realizar as coletas das amostras foram escolhidos após visitas de campo ao longo do canal. Esses foram selecionados pela representatividade da área em estudo e pela acessibilidade para coletar as amostras. $\mathrm{O}$ intuito ao escolher esses pontos foi de avaliar o comportamento das características qualitativas das águas do Canal das Piabas, visto que ele perpassa por áreas densamente 


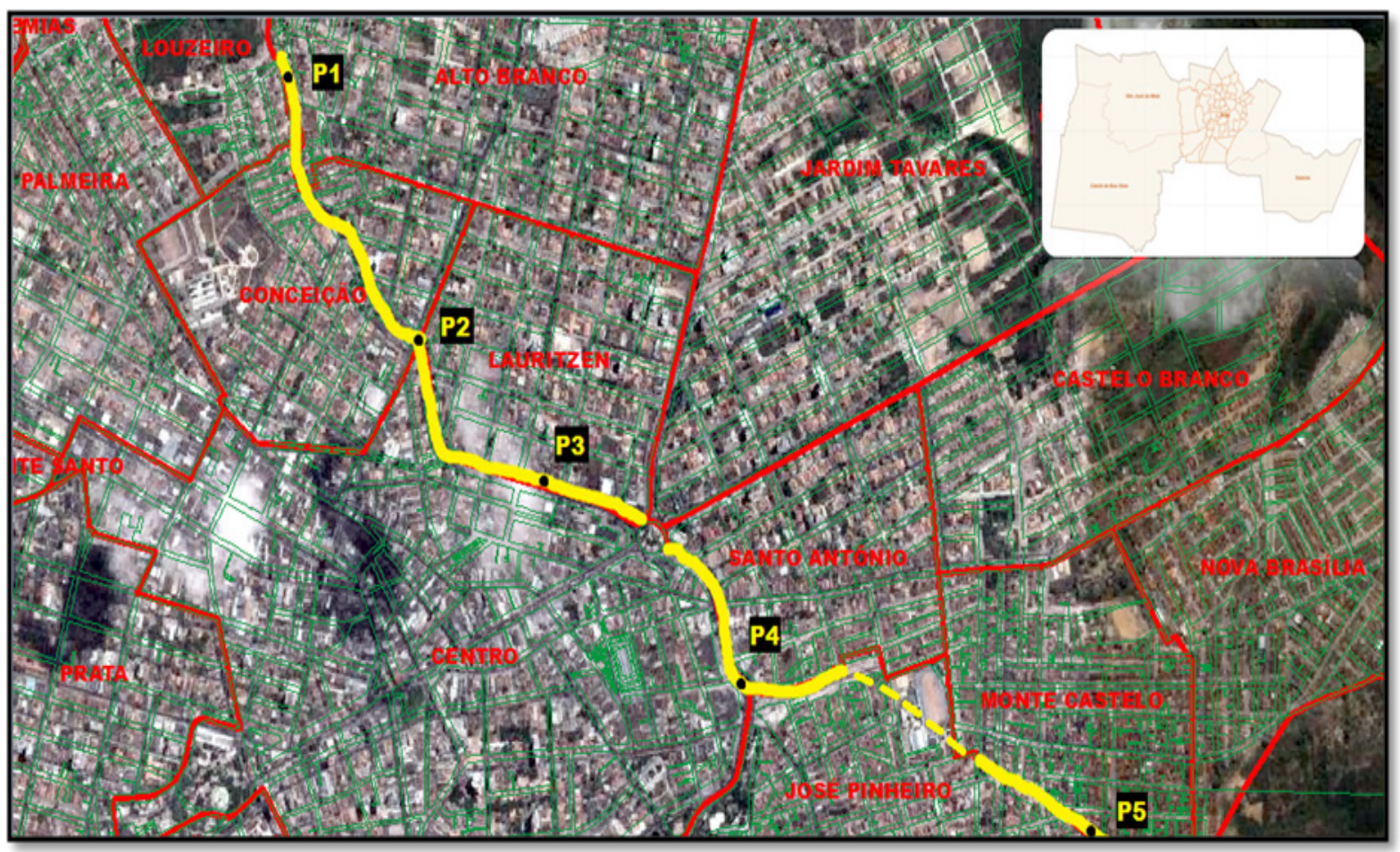

Figura 2 Mapa de localização dos pontos amostrais e delimitação da área em estudo.

Fonte: Google Earth, 2010.

povoadas e com diferentes níveis econômicos, bem como avaliar a forma de ocupação urbana e suas relações com a qualidade da água. Os mesmos foram levantados com GPS e alocados sobre a imagem de satélite do Google Earth (2010).

Durante o período do monitoramento dos pontos foram realizadas duas coletas semanais, nos horários entre as 7 e as 8 horas. Para as visitas de campo e coletas das amostras, em cada ponto, foram usados o coletor (Figura 3), duas garrafas plásticas para as amostras das análises físico-químicas e outro frasco esterilizado para as amostras das análises microbiológicas. No total foram realizadas trinta coletas em cada ponto, número estabelecido para melhor representar estatisticamente o conjunto de dados.

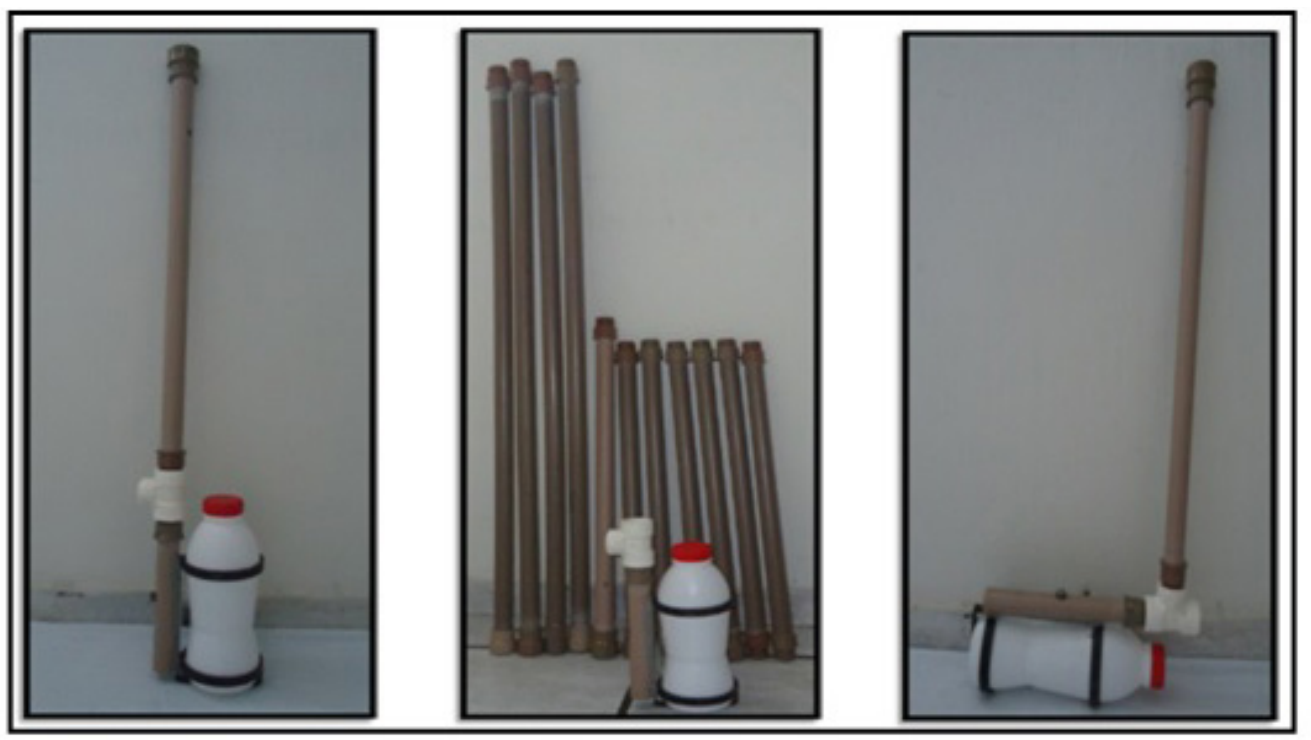

Figura 3 Material utilizado para coleta das amostras de água do Canal das Piabas.

Fonte: Autora, 2013. 
O equipamento usado como coletor é composto por um suporte de ferro acoplado a tubos de PVC, com rosca, e garrafas de plástico, para facilitar o acesso aos pontos (Figura 3).

\section{Indicadores analisados}

Os indicadores de qualidade de água adotados na realização deste trabalho foram turbidez, sólidos suspensos totais, demanda bioquímica de oxigênio (DBO), demanda química de oxigênio (DQO), oxigênio dissolvido e coliformes termotolerantes, afim de identificar contaminação por esgoto. Foi também realizada uma comparação entre os resultados dos indicadores e dados pluviométricos obtidos do Instituto Nacional de Meteorologia (INMET) com o intuito de avaliar a influência da precipitação na variação desses indicadores. As análises foram realizadas no Laboratório de Saneamento da Universidade Federal de Campina Grande, localizado no bairro de Bodocongó.

As metodologias utilizadas nas análises laboratoriais seguiram as recomendações descritas no Standard Methods for the Examination of Water and Wastewater (APHA-AWWA-WEF, 2005).

\section{RESULTADOS E DISCUSSÃO}

Durante as visitas para realização das coletas das amostras de água foi visto que são contínuas as contribuições de esgotos domésticos e o lançamento de resíduos sólidos no Canal das Piabas. Para avaliar como ocorre o comportamento das características da água, ao longo do canal, foram analisados
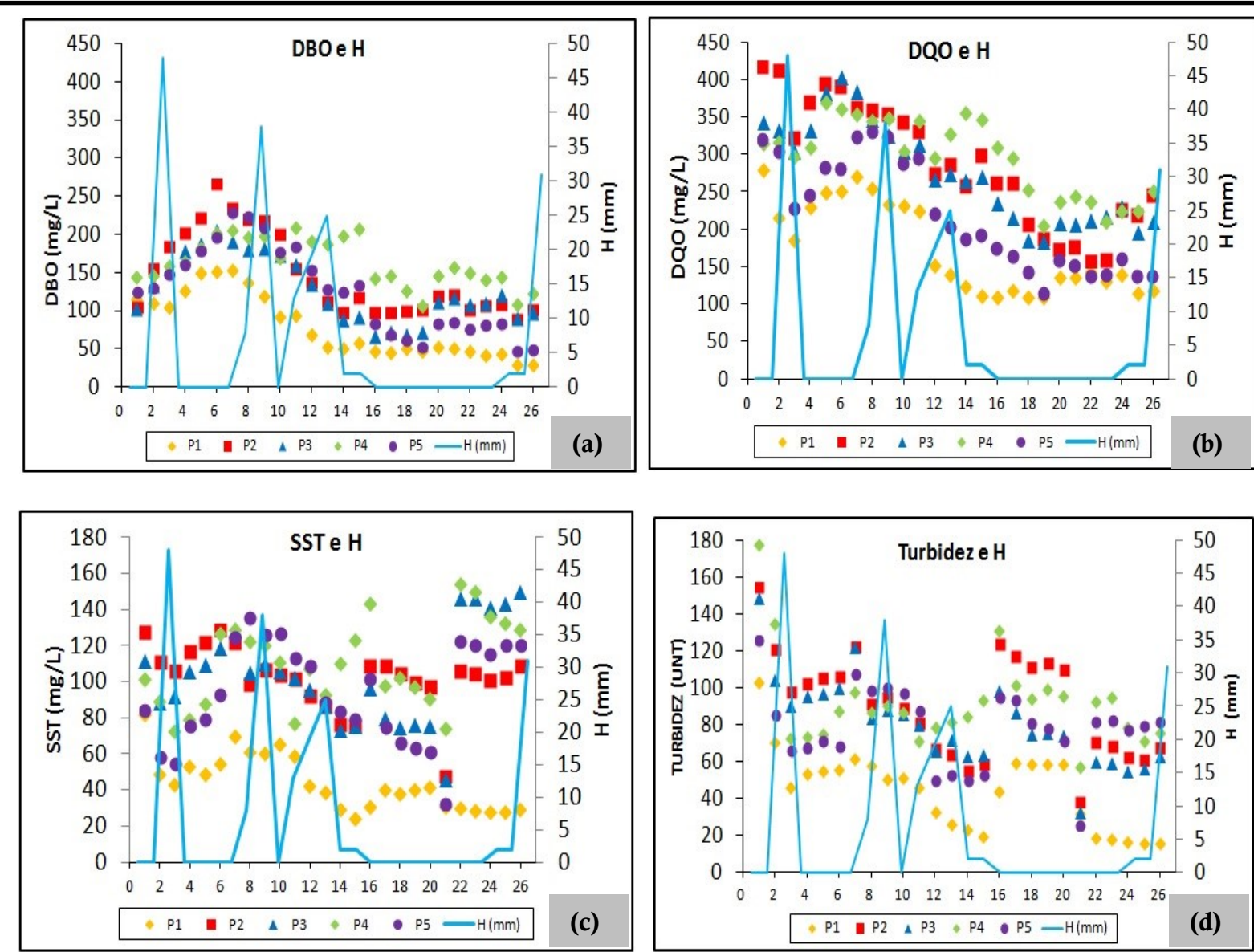

(a) DBO: Demanda Bioquímica de Oxigênio e H: precipitação;

(b) DQO: Demanda Química de Oxigênio e H: precipitação;

(c) SST: Sólidos Suspensos Totais e H: precipitação;

(d) Turbidez e H: precipitação.

Figura 4 - Variação temporal de $\mathrm{DBO}_{5}$, DQO, $\mathrm{SST}$ e turbidez, com base nas médias móveis 5 a 5, e a precipitação, em amostras coletadas nos pontos P1, P2, P3, P4 e P5, entre abril e agosto de 2013. 
alguns indicadores, cujos resultados traduzem uma situação de fragilidade do sistema de drenagem de Campina Grande

Para facilitar a apresentação e consequente interpretação dos resultados obtidos mediante a análise, em laboratório, das características das águas que contribuem para o Canal das Piabas, foi aplicada a média móvel cinco a cinco dos dados obtidos com o objetivo de atenuar as oscilações dos indicadores de qualidade de água.

Os dados pluviométricos $(\mathrm{H})$ referentes ao período de coleta das amostras de água, no canal de drenagem em estudo, foram avaliados em conjunto com as variações das concentrações de $\mathrm{DBO}_{5}$, DQO, SST e turbidez, para os cinco pontos amostrais, cujas relações estão ilustradas na Figura 4 a, $\mathrm{b}$, c e d, respectivamente. Foram observadas as elevadas concentrações de $\mathrm{DBO}_{5}$ e $\mathrm{DQO}$ nos cinco pontos analisados. Contudo, o ponto P1 apresentou concentrações abaixo dos demais pontos, referentes às concentrações de material orgânico, material fecal e materiais em suspensão, evidenciando a contaminação ao longo do canal, e mostrando a ineficiência do sistema adotado.

Através da Figura 4 a e b, percebe-se a influência da precipitação pluviométrica, visto que, em determinado momento, há um decaimento nas concentrações das variáveis (DBO e DQO). Isso ocorre devido ao período chuvoso que proporcionou uma diluição dos esgotos que continuamente são lançados no canal.

Com os indicadores SST e turbidez (Figura $4 \mathrm{c}$ e d) percebe-se um comportamento diferente em relação à precipitação. Nas coletas realizadas nos dias de ocorrência de precipitação, foi percebido um aumento da concentração para os dois indicadores, isto porque a chuva promove um arraste do material sob a superfície drenada. Contudo, visto que o canal de drenagem é aberto, os valores de SST e turbidez, recebem influência não só das contribuições das águas drenadas, como do aporte de resíduos das vias públicas e da população de forma contínua, interferindo nessas variações.

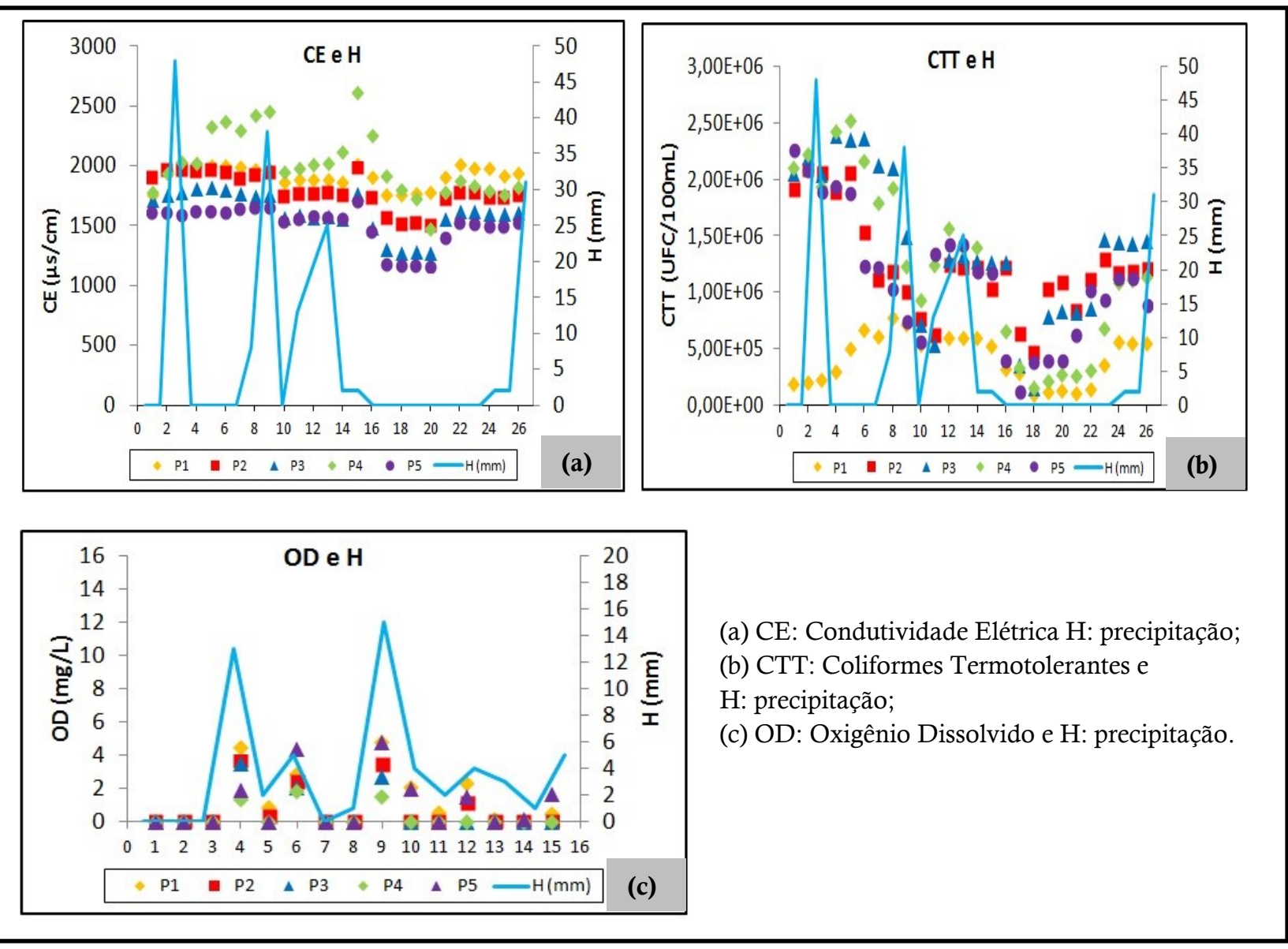

Figura 5 - Variação temporal das concentrações de CE, CTT, OD com base nas médias móveis 5 a 5 , e a precipitação, em amostras coletadas nos pontos P1, P2, P3, P4 e P5, entre abril e agosto de 2013. 
A água, ao passar pelo solo, dissolve e transporta diversos materiais, para os corpos hídricos, entre esses os sais. O mesmo acontece com o canal, à água até atingir a parte construída do canal vem em contato direto com o solo. Vale salientar que, a partir do P1, é que o Riacho das Piabas passa a ter seu curso canalizado. Na condutividade elétrica, pode-se observar um decaimento de montante (P1) para jusante (P5), isso ocorre porque há uma maior concentração de sais no ponto P1 que vão sendo diluídos ao longo do canal. Mas o ponto P4 apresenta, em alguns momentos, elevadas concentrações em relação aos demais, o que pode estar relacionado às significativas contribuições de esgoto próximas deste ponto que estão colaborando para a elevação deste indicador.

Quanto à condutividade elétrica, quando relacionada com a precipitação (Figura 5 a) pode-se observar que a precipitação não influencia de forma significativa nesse parâmetro, visto que em períodos de chuva suas concentrações apresentaram pequenas reduções.

Assim como os demais indicadores analisados, os parâmetros coliformes termotolerantes e OD (Figura 5 b e c) não fogem à realidade que vem sendo discutida até então, com relação à contaminação por efluentes domésticos no Canal das Piabas. O primeiro, após o período de chuva, apresentou alguns decaimentos em suas concentrações, mas mesmo assim, suas concentrações apresentaram-se elevadas para água de drenagem. Para o segundo parâmetro, os resultados demonstram que só há presença de oxigênio dissolvido nos dias em que há precipitação, pois nos demais dias, a predominância de esgoto impede que ocorram concentrações de OD nas águas do canal.

De acordo com a Tabela1 pode-se observar as elevadas concentrações de $\mathrm{DBO}_{5}$ e DQO nos cinco pontos analisados, sendo que essas concentrações estão acima de valores encontrados na literatura referente à água de drenagem de outros países. Nos EUA com $20 \mathrm{mg} / \mathrm{L}$ de $\mathrm{DBO}_{5}$ e $115 \mathrm{mg} / \mathrm{Lde}$ DQO, e na Coreia com $\mathrm{DBO}_{5}$ de $83 \mathrm{mg} / \mathrm{L}$ e $\mathrm{DQO}$ de $197 \mathrm{mg} / \mathrm{L}$ (VALE, 2011). As concentrações desses indicadores na água pluvial de Campina Grande também ficaram acima dos valores encontrados no Brasil, como em Brasília onde foram encontrados valores de 55,3 mg/L DQO e 22,1 mg/L DBO (Campanha et al., 2007).

Segundo Jordão e Pessôa (2011), pode-se afirmar que a água do canal em estudo se caracteriza como esgoto doméstico, visto que a $\mathrm{DBO}_{5}$ e a $\mathrm{DQO}$ se enquadram nas faixas estimadas pelos autores, de 100 a $400 \mathrm{mg} / \mathrm{L}$ e de 200 a $800 \mathrm{mg} / \mathrm{L}$, respectivamente. Diante dos dados de DBO e DQO obtidos na análise das amostras (Tabela 3.1), conclui-se que a água de drenagem pode ser classificada como um esgoto fraco.

As médias de SST apresentados nos cinco pontos analisados variam de 43 a $103 \mathrm{mg} / \mathrm{L}$, aproximando-se de valores observados nos EUA que são de 67 a $101 \mathrm{mg} / \mathrm{L}$, e das concentrações registradas na Suíça de 64 a $182 \mathrm{mg} / \mathrm{L}$, de acordo com Vale (2011).

Comparando os valores de CTT de 9,53E+05/100mL, do ponto P1 (menos poluído), com os valores encontrados no trabalho de Lima (2013), que determinou CTT no sistema de esgoto de Campina Grande e obteve em média 1,46E+07/100mL, superior aos números determinados neste trabalho. Mas quando comparados com dados de Campanha (2007) que registrou 2,36E+5/100mL nas águas pluviais de Brasília, as águas de drenagem de Campina Grande apresentaram concentrações elevadas.

As elevadas concentrações dos indicadores analisados se justificam diante dos fatos vistos em campo, tais como, contínuas contribuições de esgotos e presença de resíduos sólidos lançados pelos moradores (Figura 6). Durante a realização das coletas não foi presenciada nenhuma ação de manutenção e limpeza no canal. Suas paredes encontram-se, na maior parte do canal, com estrutura conservada ou pouco desgastada. Embora não tenha sido presenciado, foi informado por parte da Prefeitura Municipal, mediante a Secretaria de Serviços Urbanos e Meio Ambiente (SESUMA), que os serviços de coleta de resíduos sólidos nas imediações do canal e dentro dele são realizadas periodicamente.

Os pontos P2, P3, P4 e P5 são os que apresentaram as maiores concentrações, devido às significativas contribuições de esgotos nesses pontos. Como verificado em campo, o $\mathrm{P} 2$ recebe contribuições de oficinas, o P3, além de outras contribuições no seu trecho, é influenciado pelo ponto a montante, o ponto P4, além das contribuições dos pontos anteriores, recebe efluente da feira central, e o ponto P5, consequentemente, também encontra-se poluído, apesar de apresentar concentrações menores. Isso vem de encontro à questão levantada até então, evidenciando que o Canal das Piabas recebe contínuas contribuições de esgotos no seu percurso 
Tabela 1- Parâmetros descritivos das variáveis, físicas, químicas e microbiológicas determinadas nos pontos de monitoração entre abril e agosto de 2013.

\begin{tabular}{|c|c|c|c|c|c|}
\hline VARIÁVEL & $\mathbf{P}$ & $\mathbf{N}$ & MÉD & MíN & MÁX \\
\hline \multirow{5}{*}{$\begin{array}{l}\text { Turbidez } \\
\text { (UNT) }\end{array}$} & P1 & 30 & 45 & 6 & 146 \\
\hline & P2 & 30 & 93 & 13 & 339 \\
\hline & P3 & 30 & 87 & 11 & 306 \\
\hline & P4 & 30 & 101 & 21 & 324 \\
\hline & P5 & 30 & 78 & 5 & 258 \\
\hline \multirow{5}{*}{$\begin{array}{c}\mathrm{SST} \\
(\mathrm{mg} / \mathrm{L})\end{array}$} & P1 & 30 & 44 & 6 & 127 \\
\hline & $\mathrm{P} 2$ & 30 & 98 & 15 & 269 \\
\hline & P3 & 30 & 94 & 17 & 274 \\
\hline & $\mathrm{P} 4$ & 30 & 103 & 26 & 300 \\
\hline & P5 & 30 & 81 & 5 & 238 \\
\hline \multirow{5}{*}{$\begin{array}{c}\text { DBO } \\
(\mathrm{mg} / \mathrm{L})\end{array}$} & $\mathrm{P} 1$ & 30 & 81 & 14 & 212 \\
\hline & $\mathrm{P} 2$ & 30 & 138 & 32 & 380 \\
\hline & P3 & 30 & 122 & 26 & 305 \\
\hline & $\mathrm{P} 4$ & 30 & 158 & 54 & 320 \\
\hline & P5 & 30 & 117 & 11 & 302 \\
\hline \multirow{5}{*}{$\begin{array}{c}\text { DQO } \\
(\mathrm{mg} / \mathrm{L})\end{array}$} & $\mathrm{P} 1$ & 30 & 180 & 50 & 446 \\
\hline & P2 & 30 & 292 & 92 & 641 \\
\hline & P3 & 30 & 282 & 121 & 615 \\
\hline & $\mathrm{P} 4$ & 30 & 299 & 115 & 532 \\
\hline & P5 & 30 & 218 & 68 & 559 \\
\hline \multirow{5}{*}{$\begin{array}{c}\mathrm{CE} \\
(\mu \mathrm{s} / \mathrm{cm})\end{array}$} & P1 & 30 & 1907 & 1282 & 2270 \\
\hline & $\mathrm{P} 2$ & 30 & 1816 & 1002 & 2100 \\
\hline & P3 & 30 & 1645 & 819 & 1936 \\
\hline & P4 & 30 & 2001 & 382 & 3400 \\
\hline & P5 & 30 & 1554 & 975 & 1928 \\
\hline \multirow{5}{*}{$\begin{array}{c}\text { CTT } \\
(\mathrm{UFC} / 100 \mathrm{~mL})\end{array}$} & P1 & 30 & $9,53 \mathrm{E}+05$ & $1,00 \mathrm{E}+04$ & $4,00 \mathrm{E}+06$ \\
\hline & P2 & 30 & $3,17 \mathrm{E}+06$ & $6,20 \mathrm{E}+04$ & $1,35 \mathrm{E}+07$ \\
\hline & P3 & 30 & $1,67 \mathrm{E}+06$ & $5,75 \mathrm{E}+04$ & $5,02 \mathrm{E}+06$ \\
\hline & P4 & 30 & $1,45 \mathrm{E}+06$ & $5,02 \mathrm{E}+04$ & $3,53 \mathrm{E}+06$ \\
\hline & P5 & 30 & $1,60 \mathrm{E}+06$ & $4,16 \mathrm{E}+04$ & $5,02 \mathrm{E}+06$ \\
\hline \multirow{5}{*}{$\begin{array}{c}\text { OD } \\
(\mathrm{mg} / \mathrm{L})\end{array}$} & $\mathrm{P} 1$ & 15 & 1,3 & 0 & 4,8 \\
\hline & $\mathrm{P} 2$ & 15 & 0,7 & 0 & 3,6 \\
\hline & P3 & 15 & 0,6 & 0 & 3,5 \\
\hline & $\mathrm{P} 4$ & 15 & 0,3 & 0 & 1,8 \\
\hline & P5 & 15 & 1,1 & 0 & 4,8 \\
\hline
\end{tabular}




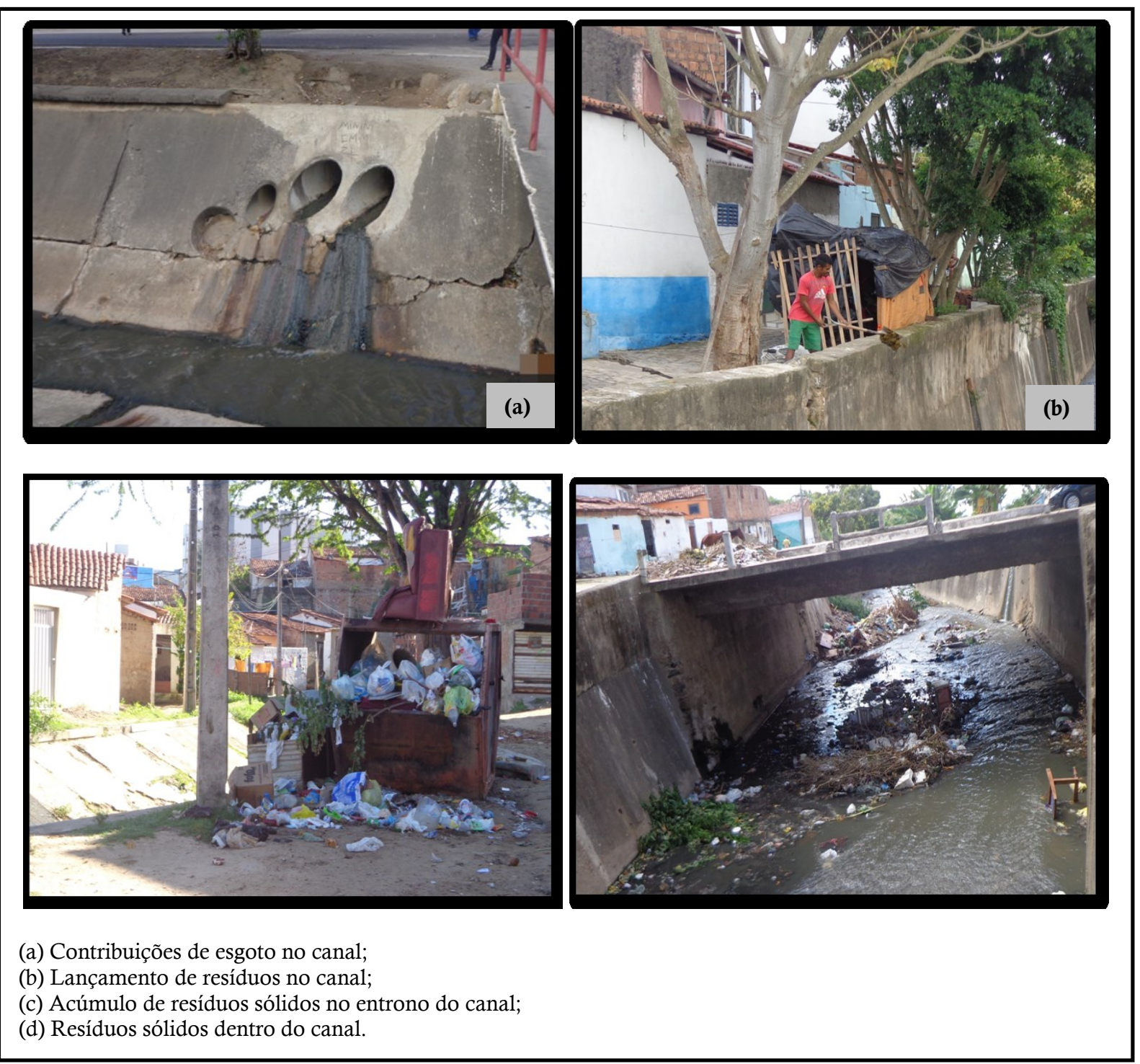

Figura 6: Contribuições de esgoto e resíduos sólidos no Canal das Piabas.

Fonte: Autora, 2013.

\section{CONCLUSÕES}

Com base nos resultados obtidos durante o monitoramento dos cincos pontos do sistema de drenagem pluvial (Canal das Piabas) de Campina Grande foi possível concluir que:

Através da análise da qualidade da água do Canal das Piabas, foi determinado que a mesma se caracteriza como esgoto doméstico fraco;

Há relação direta entre as concentrações dos indicadores analisados e a precipitação pluviométrica, visto que, após dias chuvosos, por ocorrer um arraste de matérias e aumento do volume de água drenada proporcionado pela chuva, todos os indicadores avaliados apresentam variação significativa de concentrações, exceto a condutividade elétrica;

Os pontos P2, P3, P4 e P5 foram os que apresentaram maior grau de poluição, pois além das contribuições de esgotos e lançamento de resíduos sólidos, recebem efluentes de oficinas e da feira central;

A poluição do canal ocorre devido às permanentes contribuições de esgotos, assim como pelo lançamento de resíduos por parte dos moradores associados à deficiência na limpeza urbana;

Há ineficiência na manutenção do canal de drenagem, que apresenta contribuições irregulares 
de esgoto e resíduos sólidos, caracterizando-se assim a deficiência na gestão desse sistema, assim como a falta de conscientização por parte da população;

Ao verificar que a água do Canal das Piabas se caracteriza como esgoto doméstico, que o canal é utilizado como depósito de resíduos sólidos por moradores, conclui-se que o sistema adotado não funciona como separador absoluto, expondo a população que vive próxima ao canal a riscos epidemiológicos, além de gerar degradação do ambiente.

\section{AGRADECIMENTOS}
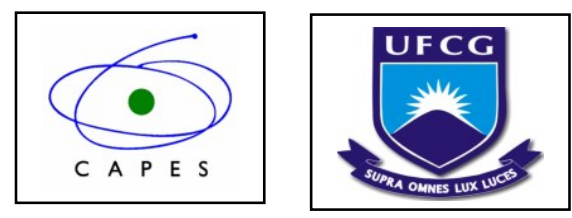

\section{REFERÊNCIAS}

CAMPANHA, N.; A. BERNARDES, R.; S. SILVA, J.; A. Controle qualitativo e quantitativo do escoamento pluvial urbano com bacias de detenção. Ambi-Agua, Taubaté, v. 2, n. 3, p. 98-111, 2007.

JORDÃO, E. P.; PESSÔA, C. A. Tratamento de esgoto doméstico. Rio de Janeiro. 6. ed. 1050 p. 2011.

LIMA, N.; F. Recuperação de ovos de helmintos em amostras de águas residuárias urbanas de populações de baixa renda da cidade de Campina Grande, Paraíba, Brasil. 2013. 72p. Dissertação (Mestrado Engenharia Civil e Ambiental) - Universidade Federal de Campina Grande. PB. 2013.

NÓBREGA, P.; V.; M. Análise do sistema de drenagem de Campina Grande/PB para proteção de áreas de risco de inundação. Campina Grande, Paraíba, Brasil. 2012. 128p. Dissertação (Mestrado Engenharia Civil e Ambiental) - Universidade Federal de Campina Grande. PB. 2012.

RAMOS, C. L; BARROS, M. T. L; PALOS, J. C. F. (coords.). Diretrizes Básicas para Projetos de Drenagem Urbana no Município de São Paulo. São Paulo: FCTH (Fundação Centro Tecnológico de Hidráulica). 289p. 1999.

SOUSA, V; G. Diagnóstico e prognóstico socioeconômico e ambiental das nascentes do Riacho das Piabas (PB). Dissertação (Mestrado). Universidade Federal de Campina Grande, Centro de Tecnologia e Recursos Naturais. Campina Grande, 2010.

SNIS, Sistema Nacional de Informações sobre Saneamento. Brasília (DF): Ministério das Cidades, Secretaria Nacional de Saneamento Ambiental, 2011.

VALE, A.; B.; M., H. Qualidade de águas pluviais em meio urbano - Caso de estudo do parque de estacionamento do Instituto Superior Técnico. Dissertação (Mestrado). Universidade de Lisboa. Set de 2011. 